\title{
Copy number of $P$ elements, $K P /$ full-sized $P$ element ratio and their relationships with environmental factors in Brazilian Drosophila melanogaster populations
}

\author{
MT Ruiz and CMA Carareto \\ Departamento de Biologia, IBILCE, Universidade Estadual Paulista, Rua Cristóvão Colombo, 2265, Jardim Nazaré, São José do Rio Preto \\ 15054-000, SP, Brazil
}

\begin{abstract}
The $P$ transposable element copy numbers and the $K P /$ fullsized $P$ element ratios were determined in eight Brazilian strains of Drosophila melanogaster. Strains from tropical regions showed lower overall $P$ element copy numbers than did strains from temperate regions. Variable numbers of full-sized and defective elements were detected, but the full-sized $P$ and $K P$ elements were the predominant classes of elements in all strains. The full-sized $P$ and $K P$ element ratios were calculated and compared with latitude. The northernmost and southernmost Brazilian strains showed fewer full-sized elements than $K P$ elements per genome,
\end{abstract}

and the strains from less extreme latitudes had many more full-sized $P$ than $K P$ elements. However, no clinal variation was observed. Strains from different localities, previously classified as having $P$ cytotype, displayed a higher or a lower proportion of $K P$ elements than of full-sized $P$ elements, as well as an equal number of the two element types, showing that the same phenotype may be produced by different underlying genomic components of the $\mathrm{P}-\mathrm{M}$ system.

Heredity (2003) 91, 570-576, advance online publication, 17 September 2003; doi:10.1038/sj.hdy.6800360

Keywords: $P$ transposable elements; $K P$ elements; $K P /$ full-sized $P$ elements; $\mathrm{P}-\mathrm{M}$ systems; Drosophila melanogaster

\section{Introduction}

After entering the Drosophila melanogaster genome by horizontal transfer from D. willistoni (Anxolabéhère et al, 1988; Daniels et al, 1990), $P$ elements have spread vertically worldwide and evolved into a heterogeneous family including the ancestral sequence and a collection of internally deleted elements. $P$ elements have been classified into two structural types: type I, which includes the full-sized $2.9 \mathrm{~kb} P$ element and elements with small deletions at the $3^{\prime}$ end, and type II, which have much larger deletions. While the full-sized $P$ element is able to encode a single $87 \mathrm{kDa}$ polypeptide that is the functional transposase (Rio et al, 1986), the defective ones cannot produce their own transposase, but they can be mobilized if this enzyme is supplied in trans.

$P$ element transposition occurs in germline cells of the progeny of a cross between males of a strain that contains $P$ elements $(\mathrm{P})$ and females devoid of $P$ elements (M). The progeny of this cross displays the $\mathrm{P}-\mathrm{M}$ hybrid dysgenesis syndrome (Kidwell et al, 1977). Since dysgenesis does not occur in the reciprocal cross, the repression of $P$ element mobilization is thought to be maternally inherited through a cytoplasmic condition not permissive for $P$ element transposition, called the $P$ cytotype. $\mathrm{M}$ cytotype, which is found in strains lacking $\mathrm{P}$

Correspondence: CMA Carareto, Departamento de Biologia, IBILCE, Universidade Estadual Paulista, Rua Cristóvão Colombo, 2265, Jardim Nazaré, São José do Rio Preto 15054-000, SP, Brazil.

E-mail: carareto@bio.ibilce.unesp.br

Received: 29 July 2002; revised: 16 June 2003; accepted: 17 July 2003 elements, allows $P$ element transposition (Engels, 1983). According to the ability to induce ( $\mathrm{P}$ activity potential) or to repress (P susceptibility) hybrid dysgenesis, strains of D. melanogaster are classified into $\mathrm{P}, \mathrm{Q}, \mathrm{M}^{\prime}$ and $\mathrm{M}$ phenotypes. $\mathrm{P}$ strains exhibit low to high levels of $\mathrm{P}$ activity potential and low levels of P susceptibility, while $Q$ strains show extremely low levels of both P activity and $\mathrm{P}$ susceptibility. Both types have been shown to possess 30-50 copies of $P$ elements per genome, of which about a third are the $2.9 \mathrm{~kb}$ elements and the rest are deleted derivatives (Bingham et al, 1982; Black et al, 1987; $\mathrm{O}^{\prime}$ Hare et al, 1992). $\mathrm{M}$ and $\mathrm{M}^{\prime}$ strains do not exhibit any significant level of $\mathrm{P}$ activity. $\mathrm{M}$ strains are devoid of any $P$ elements and show extremely high $P$ susceptibility (Bingham et al, 1982). On the other hand, $\mathrm{M}^{\prime}$ strains vary from extremely high to moderately low P susceptibility (Anxolabéhère et al, 1985) and possess from a few to 50 copies per genome (Anxolabéhère et al, 1984; Black et al, 1987), most of which, if not all, are defective sequences (Bingham et al, 1982; Black et al, 1987). Among them, the most frequently deleted derivative is $K P$, a type II element (deleted at positions 808-2560) that encodes a 207 aa protein that has been considered as an important repressor of transposition (Lee et al, 1996; Simmons et al, 2002).

D. melanogaster populations show different ratios of full-sized and defective $P$ elements, and their frequencies and $\mathrm{P}-\mathrm{M}$ phenotypes vary worldwide. According to Anxolabéhère et al (1989), North American populations are virtually all $P$ and $Q$, and most of them possess many full-sized $P$ elements and a mix of deleted elements. On the other hand, in North Africa, Europe and Asia, 
populations are mostly $\mathrm{M}^{\prime}$. $\mathrm{P}$ and $\mathrm{Q}$ populations are found only at the Eurasian coastline and are also found in Central Africa. European populations possess fewer full-sized $P$ elements and their frequencies gradually decrease from France to Central Asia where populations have many copies of KP elements (Black et al, 1987). In eastern China, Japan, Australia and Africa, both fullsized and $K P$ elements are the predominant classes (Todo et al, 1984; Anxolabéhère et al, 1985, 1988, 1990; Sakoyama et al, 1985; Black et al, 1987; Boussy et al, 1998; Itoh et al, 1999, 2001; Itoh and Boussy, 2002). These data show that full-sized $P$ and $K P$ elements are the predominant classes in all populations, excepting those from the Americas, which seem to possess many other defective elements. O'Hare et al (1992), for example, found seven full-sized $P$ and two KP elements, and 19 other defective elements in a single strain. Since the available information about the South American populations seems to be restricted to just one population from Peru (Black et al, 1987), in this study we determined the overall copy number and the ratio of full-sized $P$ and $K P$ elements, aiming for a better understanding of the geographical differentiation of D. melanogaster populations in Brazil. In addition, we addressed the question whether the environmental factors, namely latitude or temperature, exert any influence on $P$ element copy numbers and $K P /$ full-sized $P$ element ratios.

\section{Material and methods}

\section{Strains}

D. melanogaster isofemale lines from eight distant Brazilian regions were set up from collections made in 1996-2000, and were maintained in laboratory as highly inbred small cultures since then. The strains had already been classified according to the P-M phenotype by Vetorazzi et al (1999) as moderate P (MA, from São Luis-MA and PI, from Teresina-PI; MG, from Santana do Riacho-MG and SP, from São José do Rio Preto-SP), Q (PR, from Maringá-PR and $\mathrm{RS}_{2}$, from Porto Alegre-RS) and $\mathrm{M}^{\prime}$ (SC, from Joinville-SC). The strain $\mathrm{RS}_{1}$ (from Santa Maria-RS) had not been classified according to the P-M system. The strain Harwich-w (strong P) was used as a control. Figure 1 indicates the localities from which the strains were collected.

\section{Southern blot analysis}

Genomic DNA was isolated from pools of about 50 individuals. Approximately $5 \mu \mathrm{g}$ of genomic DNA of each strain was digested with the SalI, AvaII and DdeI restriction endonucleases, aiming to investigate the overall number of $P$ element copies, and the proportion of full-sized $P$ and $K P$ elements. The blots were hybridized with the ECL hybridization buffer (Amersham Pharmacia Biotech do Brasil ${ }^{\mathrm{TM}}$ ) and the appropriate probes. DNA digested with St>alI was probed with a $764 \mathrm{bp} 5^{\prime}-$ end sequence of $D$. melanogaster $P$ element amplified from the p $\pi 25.1$ plasmid (Houck et al, 1991). DNA digested with AvaII was probed with a $2.9 \mathrm{~kb}$ sequence amplified from p $\pi 25.1$ (Haring et al, 1995), and DNA digested with DdeI was probed with a 896 bp fragment obtained by $P$ element digestion with PvuII (Figure 2). The DNA fragments were then electrophoresed, transferred to nylon membrane and fixed. The membranes

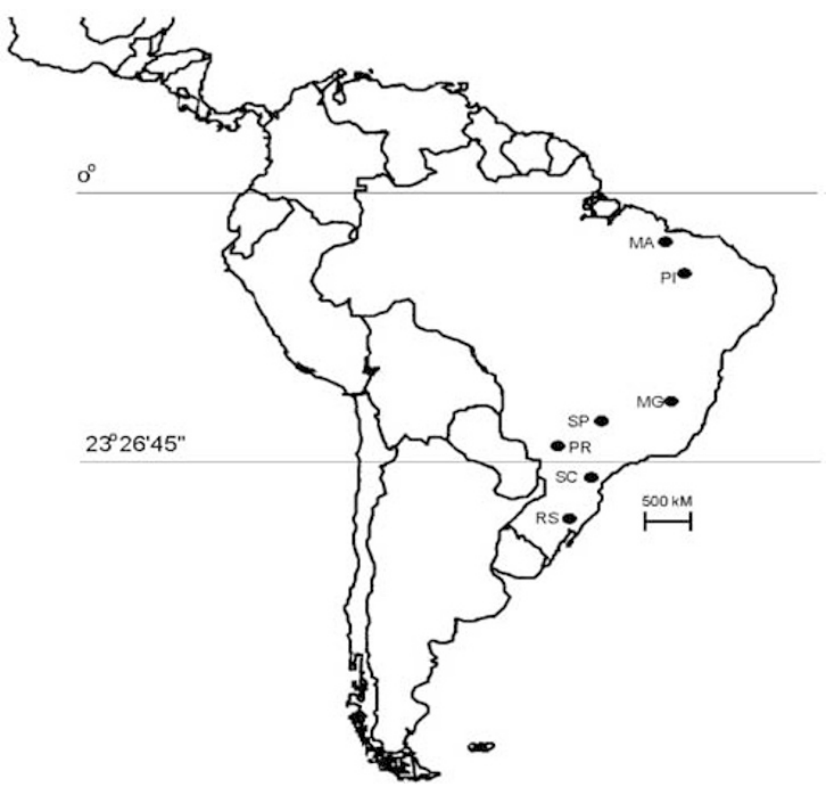

Figure 1 Map of Brazil with the localities on which the flies were collected and the respective latitudes. MA: São Luis, $2.31^{\circ}$ Slat; PI: Teresina, PI, $5.09^{\circ} \mathrm{S}$ lat; MG: Santana do Riacho, MG, $18.20^{\circ} \mathrm{S}$ lat; SP: São José do Rio Preto, SP, $20.49^{\circ}$ S lat; PR: Maringá, PR, $23.25^{\circ} \mathrm{S}$ lat SC: Joinville, SC, $26.18^{\circ}$ Slat; $\mathrm{RS}_{1}$ : Santa Maria, RS, $29.41^{\circ} \mathrm{S}$ lat and $\mathrm{RS}_{2}$ : Porto Alegre, RS, $30.02^{\circ} \mathrm{S}$ lat.

\section{a Full-sized $P$ element $=2.9 \mathrm{~kb}$}

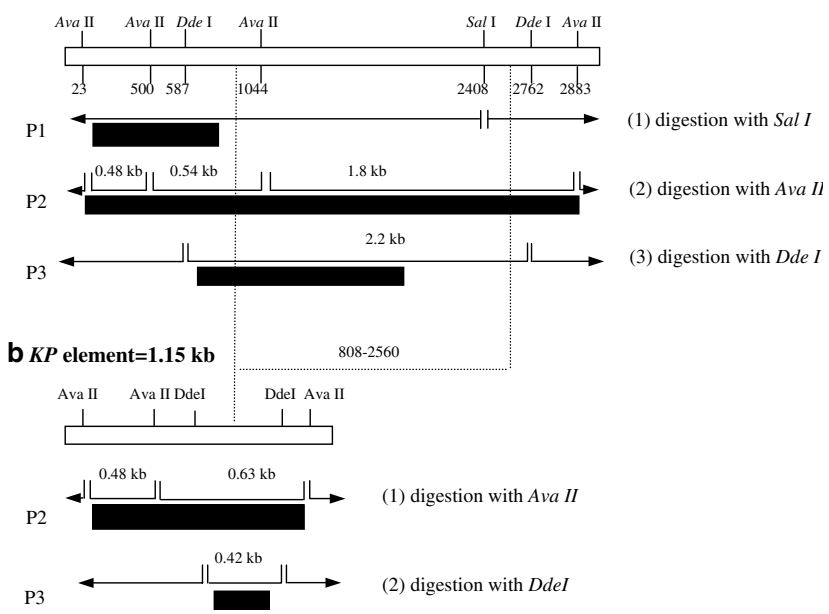

Figure 2 Maps of $P$ elements indicating the restriction sites of the endonucleases used in the analyses, the restriction fragments produced by each one and the location where the used probes anneal: (a) full-sized $P$ element and (b) KP element. Restriction sites (vertical lines), restriction fragments (broken horizontal lines) and probes (black boxes) are indicated. (a1) SalI restriction fragment and probe (P1: $764 \mathrm{bp} 5^{\prime}$-end sequence of $D$. melanogaster $P$ element) used to estimate $P$ element copy number analysis. AvaII restriction fragments and probe (P2: $2.9 \mathrm{~kb} P$ element sequence contained p $\pi 25.1$ plasmid) used to identify both full-sized $P$ element (a2) and $K P$ element (b1). DdeI restriction fragments and probe (P3: PuvI restriction fragment of $P$ element contained in $\mathrm{p} \pi 25.1$ plasmid) used to identify $K P$ element (a3 and $\mathbf{b} \mathbf{2}$ ).

were washed for $40 \mathrm{~min}$ in primary buffer containing urea (6 M urea, $0.4 \mathrm{SDS}$ and $0.5 \mathrm{M} \times \mathrm{SSC}$ ), at $42^{\circ} \mathrm{C}$, and for $10 \mathrm{~min}$ in secondary buffer $(2 \times \mathrm{SSC})$ at room temperature. 
Relative proportion of full-sized $P$ and $K P$ elements Scanning densitometry was performed by rendering the Southern blot autoradiographs as TIFF files, and the images were analysed with the public domain image analysis software NIH image ver. 1.60 (http://rsb.info.nih.gov/nih-image). The relative numbers of full-sized $P$ and $K P$ elements in each strain were estimated by calculating the ratio of the observed band densities for $K P$ and full-sized $P$ elements. For the statistical analysis, the $K P / P$ element ratios were $\log _{10}$-transformed.

\section{Statistical analysis}

Linear regression analysis was performed to evaluate the influence of latitude on copy number and the $K P / P$ element ratios of each strain, as well as the influence of the overall copy number on the $K P / P$ element ratios. The influence of mean annual temperatures of the localities where the collections were made on copy number was also tested by Student's $t$-tests. For this analysis, the strains were grouped into two classes. The first class included the strains MA and PI, from populations of equatorial regions, with elevated mean temperature all year long (above $22^{\circ} \mathrm{C}$ and up to $40^{\circ} \mathrm{C}$ in the summer), and SP, from a population of a tropical region (mean annual temperatures above $22^{\circ} \mathrm{C}$ with lows rarely below $15^{\circ} \mathrm{C}$ in the winter). The second class included the southeastern strain MG and the southern strains PR, SC, $\mathrm{RS}_{1}$ and $\mathrm{RS}_{2}$. MG was from a mountainous region in southeastern Brazil, with moderate temperatures in the summer and an average temperature below $12^{\circ} \mathrm{C}$ in winter and autumn. The southern strains were from a subtropical region characterized by well-defined seasons with temperatures ranging from $2^{\circ} \mathrm{C}$ to $15^{\circ} \mathrm{C}$ in the winter and $25^{\circ} \mathrm{C}$ to $35^{\circ} \mathrm{C}$ in the summer.

\section{Results}

Figure 3a and Table 1 show that the total number of $P$ elements varied among strains from nine (MA) to 19 $\left(\mathrm{RS}_{1}\right)$. Figure $3 \mathrm{~b}$ shows genomic DNA digested with AvaII and probed with $2.9 \mathrm{~kb} P$ element sequence amplified from $\mathrm{p} \pi 25.1$. The 1.8 and $0.48 \mathrm{~kb}$ bands present in all lines correspond to the expected sizes of an AvaIIdigested $2.9 \mathrm{~kb} P$ element. The $0.54 \mathrm{~kb}$ band runs with the $0.48 \mathrm{~kb}$ band in agarose gels and cannot be easily distinguished. Since the intensity of each fragment corresponds to its amount in the genome, the variation in intensity observed in the $1.8 \mathrm{~kb}$ band can be used as an indication of variation in the number of full-sized $P$ elements (smaller in MA, PI and $\mathrm{RS}_{1}$ lines). The signal intensity of the $0.63 \mathrm{~kb}$ band, which represents the $K P$ element, is very strong and, although visible in all strains, is stronger in MA, PI, SC, $\mathrm{RS}_{1}$ and $\mathrm{RS}_{2}$. The $0.48 \mathrm{~kb}$ band can be generated by the full-sized $P$ element, the $K P$ element and other defective elements with no deletion in the 22-500 nt region.

The DdeI digests, probed with a PvuII fragment, are shown in Figure 3c. All strains showed the 2.2 and $0.42 \mathrm{~kb}$ bands expected from full-sized $P$ and $K P$ elements, respectively, with variable signal intensities. Besides the full-sized $P$ and $K P$ elements, other internally deleted elements occur, with a maximum of six in the PI strain. The proportion of full-sized elements per genome seems to increase from the South to about $5.09^{\circ} \mathrm{S}$ lat, but

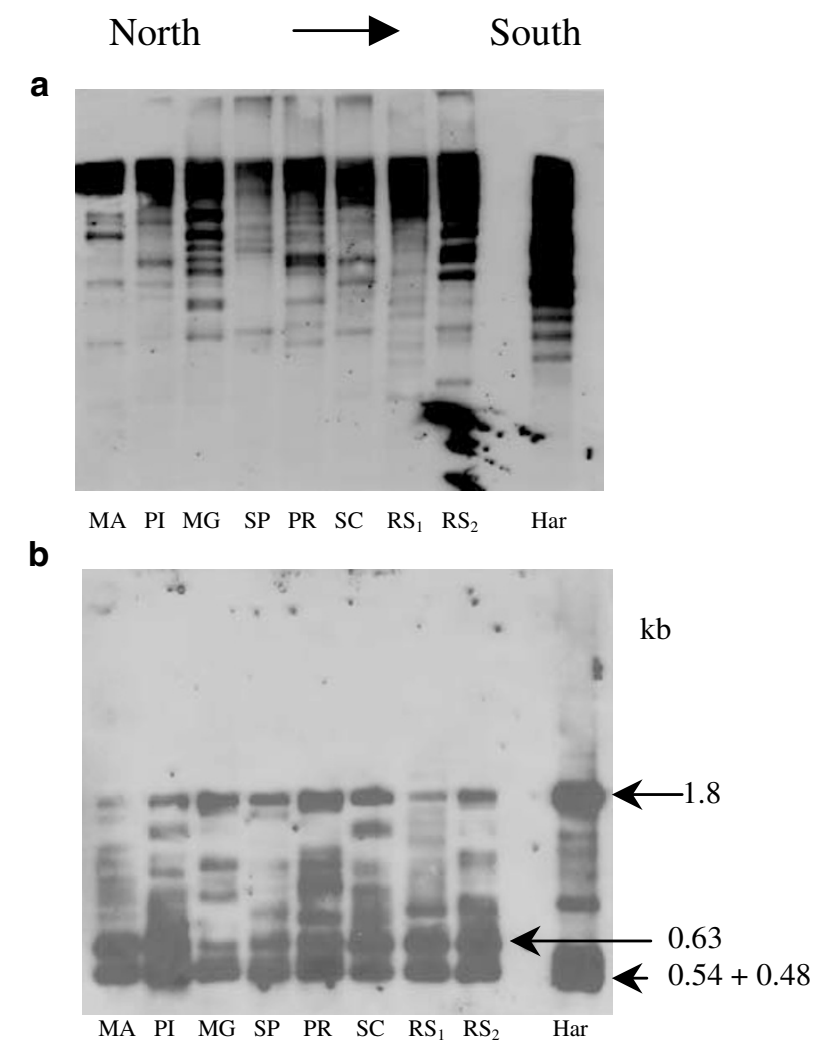

c

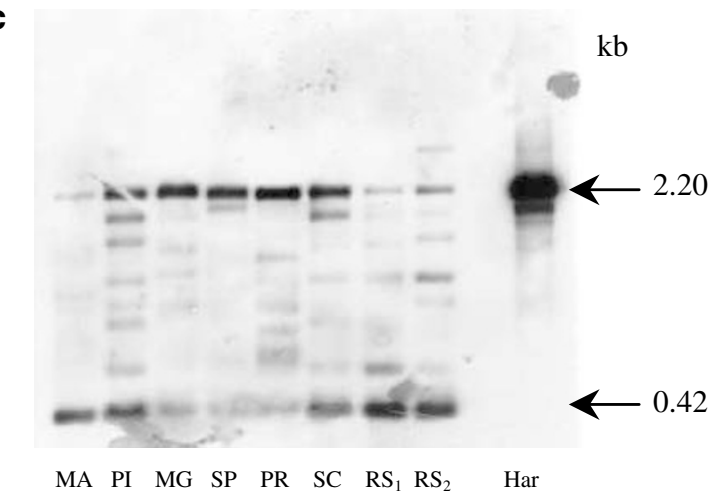

Figure 3 Southern blot analysis of genomic DNA of eight strains of D. melanogaster digested with (a) SalI and probed with a $764 \mathrm{bp} 5^{\prime}$ end sequence of D. melanogaster $P$ element; (b) AvalI and probed with a $2.9 \mathrm{~kb}$ sequence from complete $P$ element; (c) DdeI and probed with a $896 \mathrm{bp}$ fragment obtained from digestion of $P$ element with the restriction endonuclease PvuII. AvaII restriction fragments are indicated: $0.48 \mathrm{~kb}$ (produced by the full-sized $P$ and $K P$ elements), $0.54 \mathrm{~kb}$ (produced only by the full-sized $P$ element), $0.63 \mathrm{~kb}$ (produced only by $K P$ elements) and $1.8 \mathrm{~kb}$ (produced only by full-length $P$ elements). DdeI restriction fragments are indicated: $2.2 \mathrm{~kb}$ (produced only by full-sized $P$ elements), $0.42 \mathrm{~kb}$ (produced only by $K P$ elements). Lines are arranged in each blot from left to right by latitude. Har: D. melanogaster Harwich.

this qualitative pattern does not extend to MA, the northernmost population. The highest proportion of $K P$ elements per genome appears among both northernmost $\left(2.32-5.09^{\circ} \mathrm{S}\right.$ lat $)$ and southernmost $\left(29.41-30.02^{\circ} \mathrm{S}\right.$ lat $)$ populations.

The $K P /$ full-sized $P$ element ratios in the genomic DNA of a particular strain were evaluated by the ratio of 
Table $1 P$ element copy number and $K P / P$ element ratios in eight strains of D. melanogaster from Brazil

\begin{tabular}{lcc}
\hline Strains & P element overall copy number & KP/full-size P ratios \\
\hline MA & 9 & 2.30 \\
PI & 12 & 1.04 \\
MG & 19 & 0.79 \\
SP & 11 & 0.56 \\
PR & 15 & 0.64 \\
SC & 13 & 1.00 \\
$\mathrm{RS}_{1}$ & 16 & 2.15 \\
$\mathrm{RS}_{2}$ & 15 & 1.14 \\
\hline
\end{tabular}

the observed signal intensities of the expected fragment from $K P(0.42 \mathrm{~kb})$ and full-sized $P(2.2 \mathrm{~kb})$ elements. The values shown in Table 1 , which reflect the signal intensities observed in Figure 3c, indicate that the strain SP possesses the highest proportion of full-sized elements $(K P / P$ ratio $=0.56)$ and the strain $M A$ the lowest $(K P / P$ ratio $=2.30)$.

Figure 4 shows the scatter plot of the overall copy number against the log-transformed $K P / P$ ratios (Figure $4 \mathrm{a}$ ), and the scatter plots of the $K P / P$ ratios and overall copy numbers plotted against latitude (Figure $4 b, c)$. All the fitted regression lines have slopes that are not different from zero $(\log K P / P$ ratio $=0.283$ 0.0186 copies, $\mathrm{F}_{1 ; 6}=0.44, P=0.531 ; \log K P / P$ ratio $=$ 0.112-0.00437 latitude, $\mathrm{F}_{1 ; 6}=0.26, P=0.625$; copy number $=$ $10.4+0.172$ latitude, $\left.F_{1 ; 6}=2.95, P=0.137\right)$. Since the value of the copy number of the MG strain was above the $95 \%$ confidence interval, we re-evaluated the influence of latitude on the copy number of each strain excluding the value of MG (Figure 4d). In this new analysis, the fitted regression line had a significant slope (copy number $=9.45+0.182$ latitude, $F_{1 ; 5}=10.11$, $P=0.025)$. In order to test the hypothesis that temperature was the underlying factor responsible for the above dependence, we grouped the strains into two classes: those from equatorial and tropical climates (Maranhão, Piauí, and São Paulo) and those from temperate climates (Minas Gerais mountain region, Santa Catarina and Rio Grande do Sul), as described in Material and methods. In agreement with the second regression analysis, the strains from the warmer climates exhibited a significantly lower number of $P$ elements $\left(t_{7}=3.74 ; P=0.013\right)$.

\section{Discussion}

Copy number and environmental factors

$P$ element copy numbers in $D$. melanogaster populations vary worldwide. The values reach 50 copies in North America (Ronsseray et al, 1989), 30 in Western Europe (Anxolabéhère et al, 1985) and only 12 copies in Russia

Figure 4 Regression analyses of the overall $P$ element copy number against the ratio of $K P /$ full-sized $P$ elements per genome and both values against the latitudes of the localities where the $D$. melanogaster flies were collected. (a) $K P /$ full-sized $P \log$ transformed ratio against overall copy number; (b) $K P /$ full-sized $P$ against latitude; (c) overall $P$ element copy number against latitude; (d) overall $P$ element copy number against latitude, excluding the MG copy number and latitude values. The fitted linear regression lines are shown (solid lines) as well as the 95\% confidence intervals (dotted lines).
(Biémont et al, 1990), suggesting a western-eastern gradual reduction of copy numbers. The overall copy numbers of $P$ elements in Brazilian $D$. melanogaster

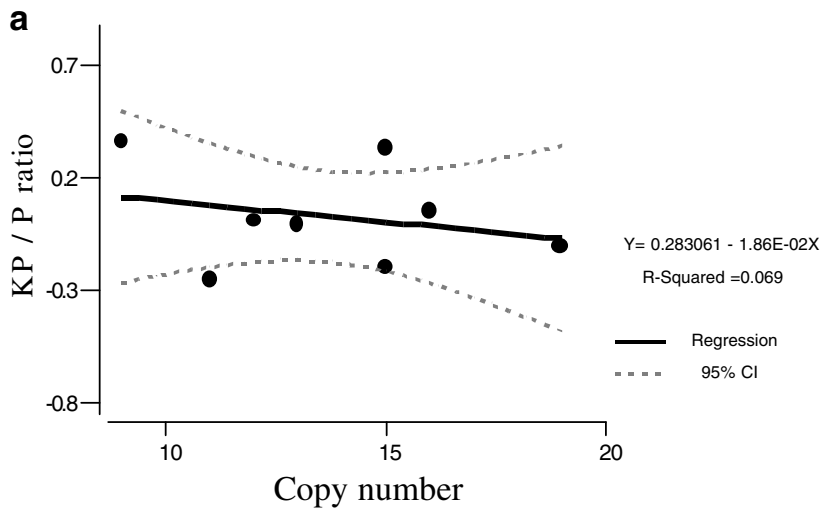

b

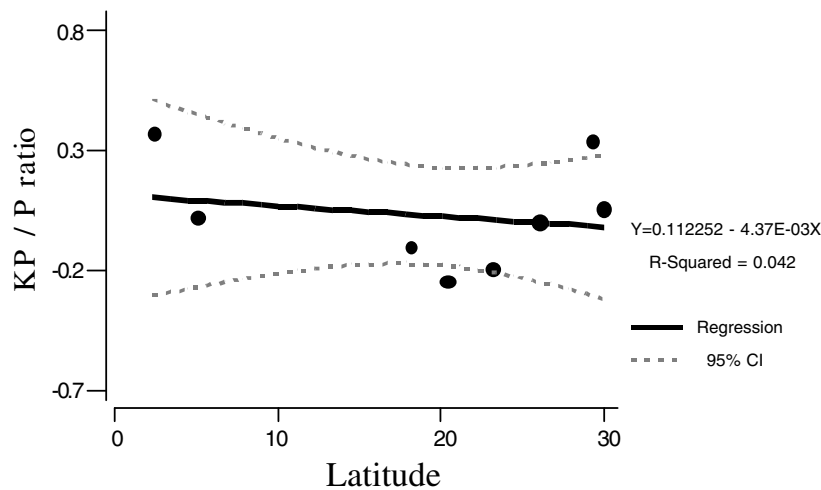

C

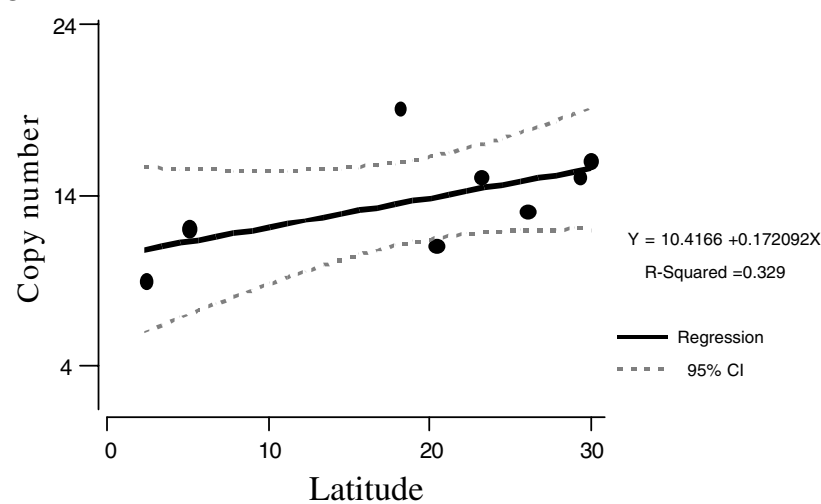

d

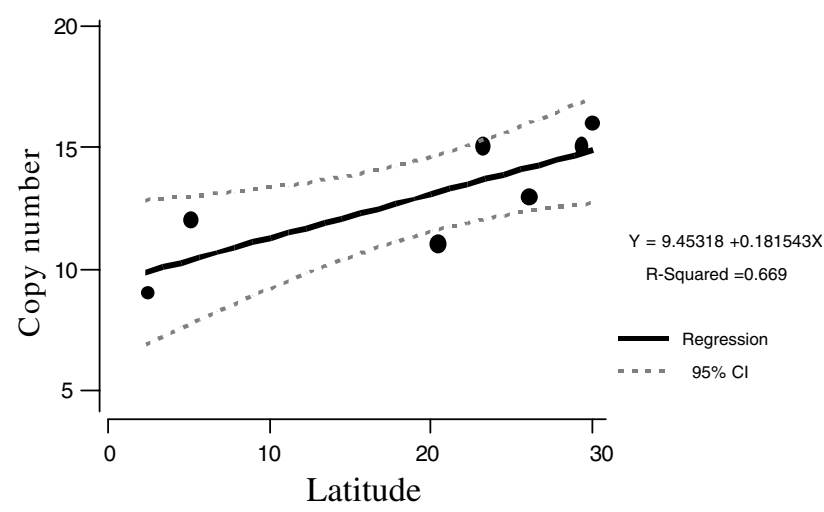


populations varied from 9 to 19 (13.75 \pm 3.15 copies), resembling more the Eurasian populations than the North American ones. The variation observed between the strains was lower than that expected, since the geographic variation in mean copy number as well as the Poisson variation between individuals within populations would contribute to a higher variation among the eight populations. However, since the strains have been maintained in laboratory in small mass cultures, their small population sizes could have produced high frequencies of transposable element sites even though the expected variance is Poisson, as predicted by Brookfield and Badge (1997).

Taken together, the regression analysis of the overall $P$ element copy number on latitude, and the comparison of the $P$ element copy number of strains from equatorial/ tropical regions and subtropical regions, allow us to suggest that variation on the $P$ element copy number is under the influence of the temperature of the original location of each population. Although indirectly evaluated, by grouping the strains according to the mean annual temperature of their original locations, the strains derived from populations of equatorial and tropical regions showed $P$ element copy numbers significantly lower (nine in MA to 11 in SP) than those from temperate regions (15 in $\mathrm{RS}_{2}$ to 19 in $\mathrm{MG}$ ). The approach of grouping the strains was chosen because temperature is variable and well defined with highs and lows in the seasons of the southern regions, very different from the warmer temperatures almost all year long found in the southeastern or northern regions. Direct relationships between environmental conditions and transposable element copy number have not been reported in natural populations (Boussy et al, 1988). However, indirect evidence suggesting a negative correlation between minimal environmental temperature and the 412 element copy number was found in $D$. simulans (Vieira and Biémont, 1996; Vieira et al, 1998). It could be argued that temperature can impose a selective pressure and might regulate the overall $P$ element copy number in natural populations from regions with high temperatures throughout the year, since the frequency of genetic abnormalities brought about by the $P$ element transposition rises dramatically in dysgenic flies reared above $25^{\circ} \mathrm{C}$ (Engels and Preston, 1979; Schaefer et al, 1979). However, it cannot be ignored that copy number might also be regulated by host genes whose frequencies vary with environmental conditions (Corces and Geyer, 1991; Costa et al, 1992; Oakeshott et al, 1992; Bhadra et al, 1997). Even the observed correlation might arise by chance if the nearby populations had similar copy numbers and the climate were also geographically clustered.

\section{Copy number, ratios of full-sized $P$ and $K P$ elements and P-M phenotypes}

Although the numbers of full-sized $P$ and $K P$ elements were not directly evaluated, their relative amounts were deduced from the variation in the band intensity of the 2.2 (full-sized $P$ ) and $0.42 \mathrm{~kb}(K P)$ fragments generated by DdeI. The full-sized $P$ and the defective $K P$ elements were the predominant types in all the Brazilian $D$. melanogaster strains. These two classes of elements occur with different proportions in different strains: three strains exhibited proportionally more full-sized $P$ than
$K P$ elements (MG, SP, PR), three others showed approximately the same proportion (PI, SC, $\mathrm{RS}_{2}$ ) and the final two possess more $K P$ than full-sized $P$ elements (MA and $\mathrm{RS}_{1}$, the northernmost and southernmost Brazilian strains, respectively). Other internally deleted elements also occur, but in lower numbers, as deduced from the signal intensity of the bands between those of 2.2 and $0.42 \mathrm{~kb}$. The predominance of full-sized $P$ plus $K P$ elements in the genomes of most populations around the world has been pointed out by Itoh and collaborators (Itoh and Boussy, 2002; Itoh et al, 2001), based on their own surveys or on other authors (Boussy et al, 1988; Nitasaka and Yamazaki, 1994; Bonnivard and Higuet, 1999; French et al, 1999; Itoh et al, 2001; Itoh and Boussy, 2002). Itoh and Boussy (2002) wondered whether this could be the final equilibrium state of the $D$. melanogaster genomes in nature, and suggested that further surveys of wild populations are required. These authors recommended these surveys especially because such predominance was not predicted by any of the theoretical models that have been carried out to evaluate $P$ element population dynamics (Brookfield, 1991, 1996; Queseneville and Anxolabéhère, 1997, 1998). Moreover, our study shows that the Brazilian populations seem to be more similar to the Eurasian than the North American ones. No matter what the relative proportions are, the fullsized $P$ and $K P$ elements seem to be predominant classes of elements in populations of $D$. melanogaster from very distant regions of Brazil (2.31-30.02 ${ }^{\circ}$ lat).

The observation of hybrid dysgenesis in crosses between strains of $D$. melanogaster could mean that they have functional $P$ elements. The ability of a strain to induce ( $\mathrm{P}$ activity potential) or to repress ( $\mathrm{P}$ susceptibility) transposition has often been assayed by gonadal dysgenesis (GD) tests, which are done by crossing unknown strains to the standard $\mathrm{M}$ (cross A) and P (cross A*) strains (Kidwell et al, 1977; Engels and Preston, 1980). The molecular basis of the P-M system has been shown to be quite complex. Our data showed a lack of influence of the overall $P$ element copy number or the relative proportion of the full-sized $P$ and the $K P$ elements $(K P / P$ ratios) on the $P$ activity potential or the $P$ susceptibility (GD $A$ and $A^{*}$ indices from Vetorazzi et al (1999), respectively) of each strain (copy number $=$ 23.9-15.8 $\arcsin A-22.7 \arcsin A^{*}, \quad \mathrm{~F}_{2 ; 4}=1.68, \quad P=0.296$; $\log K P / P=-0.512+0.596 \arcsin A+1.32 \arcsin A^{*}, \mathrm{~F}_{2 ; 4}=$ 1.13, $P=0.409$, respectively). Disagreements among amounts and types of $P$ element and $\mathrm{P}-\mathrm{M}$ phenotypes have been found in literature. While Anxolabéhère et al (1985) reported a correlation between P-M phenotypes and the overall $P$ element numbers in Eurasian strains, Engels (1984), Todo et al (1984) and Boussy et al (1988) showed, in the American and the Australian lines, a positive correlation between the $\mathrm{P}$ activity and the number of full-sized $P$ elements, but not with the overall number of $P$ elements. The $\mathrm{P}$ activity was negatively correlated with the number of KP elements. However, such correlation was not observed in D. melanogaster samples from Japan and Tawain (Itoh et al, 2001). This absence of a clear relationship between the P-M phenotypes and the genomic $P$ element composition seems to be common. The dependence of the repressing ability of a particular deleted derivative on its insertion site, such as the $1 \mathrm{~A}$ on the $\mathrm{X}$ chromosome, might explain the inconsistencies in results aiming to demonstrate that 
certain elements (such as $K P$ ) act as repressors (Black et al, 1987; Jackson et al, 1988; Rasmusson et al, 1993; Emery et al, 1999; Marin et al, 2000).

There are probably many modes of repression in natural populations and the results of mixing different repression modes, if different populations get in contact, are presumably complex. Additionally, the finding that full-sized $P$ and $K P$ elements predominate in wild populations around the world makes this problem even more complex, once it raises the question whether this could be a final equilibrium state in D. melanogaster genomes. Further spatial, but also temporal monitoring of wild populations, especially the North American and South American ones, might contribute to clarification of this scenario.

\section{Acknowledgements}

We thank the reviewers for helpful comments on the manuscript. This research was supported by the FAPESP (grants No. 1995/192-2 and 1998/08734-1), CAPES (fellowship to MTR) and CNPq.

\section{References}

Anxolabéhère D, Kai H, Nouaud D, Périquet G (1990). The distribution of the $\mathrm{P}-\mathrm{M}$ system in Drosophila melanogaster strains from the People's Republic of China. Genet Sel Evol 22: 175-188.

Anxolabéhère D, Kai H, Nouad D, Periquet G, Ronsseray S (1984). The geographical distribution of $\mathrm{P}-\mathrm{M}$ hybrid dysgenesis in Drosophila melanogaster. Genet Sel Evol 16: 1 5-26.

Anxolabéhère D, Kidwell MG, Périquet G (1988). Molecular characteristics of diverse populations are consistent with a recent invasion of Drosophila melanogaster by mobile $P$ element. Mol Biol Evol 5: 252-269.

Anxolabéhère D, Kidwell MG, Périquet G (1989). L'histoire dúne invasión genetique. La recherche 20: 1328-1338.

Anxolabéhère D, Nouaud D, Périquet G, Tchen P (1985). Pelement distribution in Eurasian populations of Drosophila melanogaster: a genetic and molecular analysis. Proc Natl Acad Sci USA 82: 5418-5422.

Bhadra U, Pal-Bhadra M, Birchler JA (1997). A trans-acting modifier causing extensive overexpression of genes in Drosophila melanogaster. Mol Gen Genet 254: 621-634.

Biémont C, Ronsseray S, Anxolabéhere D, Izaabel H, Gautier C (1990). Localization of $P$ elements, copy number regulation, and cytotype determination in Drosophila melanogaster. Genet Res 56: 3-14.

Bingham PM, Kidwell MG, Rubin GM (1982). The molecular basis of P-M hybrid dysgenesis: the role of the $P$ element, a $\mathrm{P}$ strain specific transposable element family. Cell 29: 995-1004.

Black DM, Jackson MS, Kidwell MG, Dover GA (1987). KP elements repress $P$-induced hybrid dysgenesis in Drosophila melanogaster. EMBO J 6: 4125-4135.

Bonnivard E, Higuet D (1999). Stability of European natural populations of Drosophila melanogaster with regard to the P-M systems: a buffer zone made up of Q populations. J Evol Biol 12: 633-647.

Boussy IA, Healy MJ, Oakeshott JG, Kidwell MG (1988). Molecular analysis of the $\mathrm{P}-\mathrm{M}$ gonadal dysgenesis cline in Eastern Australian Drosophila melanogaster. Genetics 119: 889-902.

Boussy IA, Itoh M, Rand D, Woodruff RC (1998). Origin and decay of the $P$ element-associated latitudinal cline in Australian Drosophila melanogaster. Genetics 104: 45-57.
Brookfield JFY (1991). Model of repression of transposition in $\mathrm{P}-\mathrm{M}$ hybrid dysgenesis by $\mathrm{P}$ cytotype and by zygotically encoded repressor proteins. Genetics 128: 471-486.

Brookfield JFY (1996). Genetic evidence for repression of somatic $P$ element movements in Drosophila melanogaster consistent with a role for the KP element. Heredity $\mathbf{7 6}$ : 384-391.

Brookfield JFY, Badge RM (1997). Population genetics models of transposable elements. Genetica 100: 281-294.

Corces VG, Geyer PK (1991). Interactions of retrotransposons with the host genome: the case of the gypsy element of Drosophila. Trends Genet 7: 86-90.

Costa R, Peixoto AA, Barbujani G, Kyriacou CP (1992). A latitudinal cline in a Drosophila clock gene. Proc $R$ Soc Biol Sci 250: 43-49.

Daniels SB, Peterson KR, Strausbaugh LD, Kidwell MG Chovinick A (1990). Evidence for horizontal transmission of the $P$ transposable element between Drosophila species. Genetics 124: 339-355.

Emery PTJ, Robinson TE, Duddington R, Brookfield FY (1999). What is the impact of transposable elements on host genome variability? Proc R Soc Lond 266: 1677-1683.

Engels WR (1983). The $P$ family of transposable elements in Drosophila. Ann Rev Genet 17: 315-344.

Engels WR (1984). A trans-acting product needed for P factor transposition in Drosophila. Science 226: 1194-1196.

Engels WR, Preston CR (1979). Hybrid dysgenesis in Drosophila melanogaster: the biology of female and male sterility. Genetics 92: 161-174.

Engels WR, Preston CR (1980). Components of hybrid dysgenesis in a wild population of Drosophila melanogaster. Genetics 95: 111-128.

French DI, Corish P, Shi M, Dover GA (1999). Evolutionary flux of $P$ element regulation in a Drosophila melanogaster hybrid dysgenesis cline. Genet Res 73: 205-216.

Haring E, Hagemann S, Pinsker W (1995). Different evolutionary behaviour of $P$ element subfamilies: M-type and O-type elements in Drosophila bifasciata and D. imaii. Gene 163: 197-202.

Houck MA, Clark JB, Peterson KR, Kidwell MG (1991). Possible horizontal transfer of Drosophila genes by the mite Proctolaelaps regalis. Science 253: 1125-1128.

Itoh M, Boussy IA (2002). Full-size $P$ and $K P$ elements predominate in wild Drosophila melanogaster. Genes Genet Syst 77: 259-267.

Itoh M, Sasai N, Inoune Y, Watada M (2001). P elements and $\mathrm{P}-\mathrm{M}$ characteristics in natural populations of Drosophila melanogaster in the southernmost islands of Japan and in Taiwan. Heredity 86: 206-212.

Itoh M, Woodruff RC, Leone MA, Boussy IA (1999). Genomic $P$ elements and $\mathrm{P}-\mathrm{M}$ characteristics of eastern Australian populations of Drosophila melanogaster. Genetica 106: 231-245.

Jackson MS, Black DM, Dover GA (1988). Amplification of KP elements associated with the repression of hybrid dysgenesis in Drosophila melanogaster. Genetics 120: 1003-1013.

Kidwell MG, Kidwell JF, Sved JA (1977). Hybrid dysgenesis in Drosophila melanogaster: a syndrome of aberrant traits including mutation, sterility, and male recombination. Genetics 86: 813-833.

Lee CC, Mul YM, Rio DC (1996). The Drosophila P-element KP repressor protein dimerizes and interacts with multiple sites on P-element DNA. Mol Cell Biol 16: 5616-5622.

Marin L, Lehmann M, Nouaud D, Izaabel H, Anxolabehere D, Ronsseray S (2000). P-element repression in Drosophila melanogaster by a naturally occurring defective telomeric P copy. Genetics 155: 1841-1854.

Oakeshott JG, Gibson JB, Anderson PR, Knibb WR, Anderson DG, Chambers GK (1992). Alchool dehydrogenase and glycerol-3-phosphate dehydrogenase clines in D. melanogaster on different continents. Evolution 36: 86-96.

O'Hare K, Driver A, McGrath S, Johnson-Schlitz DM (1992). Distribution and structure of cloned $P$ elements from the Drosophila melanogaster P strain $\pi 2$. Genet Res 60: 33-41. 
Queseneville H, Anxolabéhère D (1997). A simulation of $P$ element horizontal transfer in Drosophila. Genetics 100: 295-307.

Queseneville H, Anxolabéhère D (1998). Dynamics of transposable elements in metapopulations: a model of $\mathrm{P}$ element invasion in Drosophila. Theor Popul Biol 54: 175-193.

Nitasaka E, Yamazaki T (1994). The relationship between DNA structural variation and acitivities of $P$ elements in $P$ and $Q$ strains of Drosophila melanogaster. Heredity 73: 608-615.

Rasmusson KE, Raymond JD, Simmons MJ (1993). Repression of hybrid dysgenesis in Drosophila melanogaster by individual naturally occurring $P$ elements. Genetics 133: 605-622.

Rio DC, Laski FA, Rubin GM (1986). Identification and immunochemical analysis of biologically active Drosophila $P$ element transposase. Cell 44: 21-22.

Ronsseray S, Lehmann M, Anxolabéhère D (1989). Copy number and distribution of $P$ and $I$ mobile elements in Drosophila melanogaster populations. Chromosoma 98: 207-214.

Sakoyama Y, Todo T, Ishiwachigusa S, Honjo T, Kondo S (1985). Structures of defective $P$ transposable elements prevalent in natural Q and Q-derived M-strains of Drosophila melanogaster. Genet Res 54: 13-21.
Schaefer RE, Kidwell MG, Fausto-Sterling A (1979). Hybrid dysgenesis in Drosophila melanogaster: morphological and cytological studies of ovarian dysgenesis. Genetics 92: $1141-1152$

Simmons MJ, Haley KJ, Grimes CD, Raymond JD, Fong JCL (2002). Regulation of $P$-element transposase activity in Drosophila melanogaster by hobo transgenes that contain KP elements. Genetics 161: 205-215.

Todo T, Sakoyama Y, Chigusa SI, Fukunaga A, Honjo T, Kondo S (1984). Polymorphism in distribution and structure of $P$ elements in natural populations of Drosophila melanogaster in and around Japan. Jpn J Genet 59: 441-451.

Vetorazzi VCR, Lourenço MF, Carareto CMA (1999). The distribution of the $\mathrm{P}-\mathrm{M}$ hybrid dysgenesis system in Drosophila melanogaster strains from Brazil. Genetica 105: 273-279.

Vieira C, Aubry P, Lepetit D, Biémont C (1998). A temperature cline in copy number for 412 but not roo/B104 retrotransposons in populations of Drosophila simulans. Proc $R$ Soc Lond B Biol Sci 265: 1161-1165.

Vieira C, Biémont C (1996). Selection against transposable elements in D. simulans and D. melanogaster. Genet Res 68: 9-15. 